reduced by a factor of up to ten.

"The purpose of requiring more restrictive occupational exposure limits is to provide clear design criteria to allow engineers to design facilities to meet these kinds of standards, rather than rely on the somewhat nebulous and legally dangerous to the industry "as low as reasonably achievable' concept," he says.

The dissenting group on the BEIR committee has made it equally clear that it feels too restrictive exposure levels could place an unnecessarily heavy burden on the nuclear industry. The original minority report warns that overestimates of radiation hazard could result in "serious detriment" to national energy policy. "If the guide line levels were reduced in the way
[Radford] wants them, there would not be any nuclear industry at all' ' one committee member has been quoted as saying.

The BEIR committee dispute has been characterised as a conventional scientific disagreement. "Such controversies have existed within the scientific community since time immemorial. We will truly be in trouble when scientists passively accept each other's work without challenge,"'says Dr Sidney Marks of the Battelle Memorial Institute's Pacific North-West Laboratory.

In this case, however, the incentive has been primarily provided not by a desire for knowledge, but by a specific regulatory need; and the resulting impasse therefore carries both scientific and political dimensions. Initially the academy had hoped that this could be accommodated in the minority report; however when it emerged that over half of the BEIR committee's somatic effects subcommittee shared the reservations about the degree of support given to the linear hypothesis, it was decided that a redrafting of the whole section to produce "a more balanced expression of differing interpretations" would be more appropriate.

The new version will, it is hoped, be ready for re-submission to the full committee within a few weeks. The academy still says that "dissenting views will be published in the final report"; so whatever is agreed is unlikely to be taken as the last word.

\section{US scientists warn of environmental dangers from synthetic fuels}

As President Carter was preparing the details of a major national programme to stimulate the production of synthetic fuels, announced in his energy speech last Sunday, the Council of Environmental Quality released a report warning that a rapid increase in the use of synthetic fuels could have serious environmental consequences through speeding up the accumulation of $\mathrm{CO}_{2}$ in the atmosphere (see also page 189).

Synthetic fuels, previously a relatively unfashionable area of research, have suddenly been receiving the enthusiastic attention both of the President and of the US Congress.

Despite wide uncertainties over both economic and technical viability, the House of Representatives has already passed a bill authorising a crash development programme aimed at a target of producing 2 million barrels of synthetic fuel a day by the year 1990. And in his energy speech, delivered after almost two weeks of closeted discussion with his top advisers, President Carter proposed a programme that would develop America's alternative fuel sources from coal, oilshale, plant products and the Sun to replace 2.5 million barrels a day of imported oil by 1990 .

However both environmentalists and scientists have expressed concern at the environmental implications of such programmes, urging the President to concentrate on means for achieving energy conservation rather than the search for substitute fuels.

In a report to the $C E Q$, the four scientists say that the production of $\mathrm{CO}_{2}$ resulting from the use of synthetic fuels (such as gas or oil) made from coal is almost $50 \%$ higher than the $\mathrm{CO}_{2}$ emissions resulting from the production of energy directly from coal, and twice as high as the result of obtaining an equivalent amount of energy from natural gas.

"It is our conviction that an appropriate reaction to the mounting worldwide squeeze on supplies of energy requires consideration of the $\mathrm{CO}_{2}$ problem as an intrinsic part of any proposed policy on energy," the four scientists say.

Environmental groups have warned the President about other potentially damaging aspects of a massive synthetics fuels programmes, ranging from the disruption caused by the construction of large production plants to the creation of large quantities of carcinogenic substances.

In a letter sent to the President last week, five such groups urged that he not allow himself to be caught up in what they described as a "synfuel panic", and consider lower-cost conservation programmes as an alternative to a massive commitment to synthetic fuels.

Many of the environmental risks associated with such a commitment were "unacceptable", the groups said in their letter; emphasis should rather be placed on more solar development programmes, less costly programmes for synfuel development, and more oil and gas exploration.

Support for such a policy also came from a different direction, namely a study prepared by the Harvard Business School, soon to be published by Random House under the title "Energy Future". According to this study, the need to constrain oil imports is much greater than most economists and energy analysts have realised, since the political and other costs of dependence on a few producing countries has to be included on top of the market price for oil.

The Harvard study suggests a diverse national energy policy encouraging modest growth in the use of coal, some reliance on nuclear power, and continued efforts to develop synthetic fuels; however it argues that in the current political climate, a stepped-up programme to accelerate conservation and solar energy would prove far more rewarding than any other energy path.

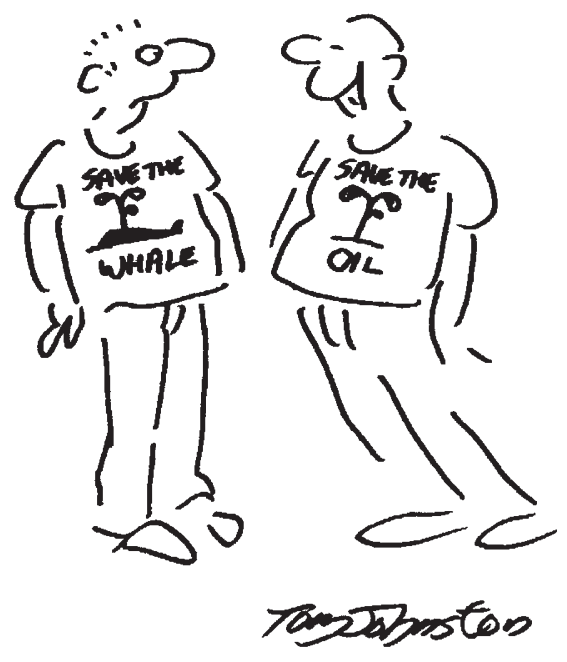

The environmental hazards associated with a major synthetic fuels programme were also covered by a report published last week by the Department of Energy's Office of Technology Impacts. Although the report says that it should be possible to find acceptable sites for large synthetic fuels production plants, it warns that successful commercialisation does have environmental risks, and that stringent environmental controls, management practices and "permitting conditions" should be maintained.

The Department report says that deployment of synthetic liquid facilities on an accelerated schedule to 1990 appears feasible in terms of current environmental constraints, although a target of 2 million barrels a day, rather than 500,000 , would bring "rapid siting difficulties".

In reaching its conclusion, the report says there is some risk that environmental research and development programmes cannot fully satisfy all existing and expected regulatory demands, but that these risks should be known by 1985 , and it is expected that appropriate control adjustments can be made.

"Reduction of these uncertainties requires refocusing of environmental research and assessment programmes to aggressively address these areas", the report says.

David Dickson 